\title{
Regula Reda braće i sestara od pokore u starohrvatskom prijevodu*
}

\begin{abstract}
Regula Trećega franjevačkog reda, koju je 18. kolovoza 1289. izdao papa Nikola IV., u kasnom srednjovjekovlju je prevedena u starohrvatski jezik. Hrvatska verzija teksta posvjedočena je $\mathrm{u}$ trima sačuvanim rukopisima pisanim glagoljicom iz ranoga novovjekovlja. Dva prijepisa postoje u zbornicima Šimuna Klimantovića, te jedan u Zborniku Śimuna Glavića. U članku se raspravlja o jeziku prijevoda i pokazuje se da je najmlađi Glavićev prijepis (HAZU Ia25, 1529-1557) tekstološki najvredniji jer su dva Klimantovićeva prijepisa pretrpjela jezičnu i stilsku redakciju. Prijevod je najvjerojatnije nastao u prvoj polovici ili oko sredine 15. stoljeća.
\end{abstract}

Franjevačku regulu Trećega reda izdao je papa Nikola IV. (Girolamo Masci), prvi franjevački papa, u buli 18. kolovoza 1289. (Inc.: Supra montem Catholicae Fidei). ${ }^{1}$ Njoj je prethodila regula Memoriale propositum iz 1221. koja se sačuvala u prijepisu iz 1228. godine. ${ }^{2}$ Regula Trećega franjevačkog reda postoji u glagoljskom pismu i u starohrvatskom prijevodu, a najstariji prijepis potječe s početka 16. stoljeća. Postoje čak tri prijepisa ovoga prijevoda:

1. Zbornik Šimuna Klimantovića I. (1501-1512; Arhiv Provincijalata franjevaca trećoredaca u Zagrebu; = K1Zb1), ${ }^{3} 11.12 \mathrm{r}-23 \mathrm{v}$;

2. Zbornik Šimuna Klimantovića II. u Berčićevoj zbirci u Petrogradu, br. 2 $(1509 ;=\mathrm{KlZb} 2),{ }^{4} 11.3 \mathrm{a}-16 \mathrm{a}$;

3. Zbornik Šimuna Glavića (HAZU Ia25, 1529-1557; = GlZb), ${ }^{5}$ 11. 8r-20r.

Tema ovoga priloga je uzajaman odnos rukopisa i vrijeme nastanka prijevoda. Obojica pisaca tih triju rukopisa bili su članovi Trećega samostanskog reda sv.

\footnotetext{
* Zahvaljujem vlč. Kristijanu Kuharu na kopijama dvaju Klimantovićevih rukopisa, kopiji Glavićeva zbornika i kopijama šest listova Andrije Čučkovića, dr. sc. Ivanu Botici na pomoći u hrvatskom tekstu izlaganja i nekim stručnim savjetima te djelatnicima Arhiva Hrvatske Akademije znanosti i umjetnosti jer su mi 17. i 18. rujna 2014. omogućili uvid u Glavićev zbornik.

$1 \quad$ Izdanje u BULLARIUM 1768: 94-97.

2 Izdanje u MEERSSEMAN 1982: 91-112.

3 A-PFT, KIZb1 11. 12r-23v; MILČETIĆ 1911: 95-100 (V.1.)

4 MILČETIĆ 1911: 104 (Napomene, br. 5); MILČETIĆ 1955: 102-103.

5 MILČETIĆ 1911: 391-396 (XI.6.); ŠTEFANIĆ 1970: 35-39 (br. 278).
} 
Franje. Ta je redovnička zajednica tijekom 15. stoljeća stekla u Hrvatskoj atribut glagoljaši (glagolae, 1483). ${ }^{6}$ Prvi je i nešto stariji Šimun Klimantović (oko 1460. - 1540.), iz Lukorana na otoku Ugljanu, ${ }^{7}$ a drugi je i nešto mlađi Šimun Glavić (oko 1490. - poslije rujna 1564.) rodom iz Šibenika. ${ }^{8}$ Klimantović bio je pisac barem četiriju rukopisa. Osim spomenutih dvaju zbornika, još je autor i rukopisa iz Berčićeve zbirke br. $1^{9}$ te rukopisa Marum manjum iz 1511. (NSK, R 3368) ${ }^{10}$.

Iz literature poznat je još jedan, četvrti prijepis Regule od Andrije Čučkovića, koji je sačuvan fragmentarno u šest listova, a čuva se kao fragment u Berčićevoj zbirci br. 4 iz 1529. godine. ${ }^{11}$ O Andriji Čučkoviću zna se samo da je bio trećoredac podrijetlom iz Dalmacije, da je rečeni rukopis vjerojatno prepisao 1529. za boravka u trećoredskom samostanu u Kopru i da je 1550. kao gvardijan trećoredskoga samostana Svete Marije na Bijaru kraj Osora podigao dva pobočna oltara u samostanskoj crkvi. ${ }^{12}$ Konstatacija da je Čučkovićev fragment dio trećoredske franjevačke regule temelji se na kolofonu 1. 6v, gdje se čita: .f.c.i. (1520 i neka) tu regulu spisahb $\check{E}(z b)$ fratar Adria čučkoviĉ́b tretoga reda b(la)ž(e)noga Frančiska Stoeĉi u s(ve)te M(a) rie Mandalene u Kopri Ûstinopuli. ${ }^{13}$ Ako ga pomno čitamo, razaberemo da nema tekstološkoga slaganja s prijevodom regule iz Klimantovićeva i Glavićeva rukopisa.

Hrvatski prijevod regule i u Klimantovića i u Glavića ima 29 poglavlja, dok je u latinskom izvorniku 20 poglavlja. Razlika u poglavljima tumači se time što je hrvatski prevoditelj uveo devet novih naslova poglavlja. Uvod, koji u latinskom tekstu nije numeriran, prvo je poglavlje u hrvatskom prijevodu, a u duljim poglavljima učinjeno je čak osam novih potpoglavlja. Nova su poglavlja sljedeća:

odb s'vršeniě v'lizeniě. k(a)p(i)t(ulb). .g. ti (14r16-17) - Ø

od'pos'ta v k(o)r(i)zmi s(veto)ga M(a)rt(i)na. k(a)p(i)t(ulb). .j. (16v7) - Ø

od'zadušiě kako se ima činiti. k(a)p(i)t(ulb). .ž.ï. te (19v3-4) - Ø

od' naučeniě o(tb) ca te br(a)tie. k(a)p(i)t(ulb). .dz.ï. (19v18) - Ø

od'mučaniě. k(a)p(i)t(ulb). .z.ï. (20r2) - Ø

odb s'provoeniě. kapitulb. i.a. (20r20-21) - Ø

od' pomoci umirajucihb. k(a)p(i)t(ulb). .i.b. (20v11) - Ø

od'potvr'eniě regule. $\mathrm{k}(\mathrm{a}) \mathrm{p}(\mathrm{i}) \mathrm{t}(\mathrm{ulb})$. .i.dz. (23r12) - Ø.

6 RUNJE 2012: 16.

7 PETROVIĆ 2009. Novija istraživanja o njemu i njegovim spisima vidi u SRDOČ-KONESTRA I LAJŠIĆ 2008; ŠTRKALJ-DESPOT 2010; RUNJE 2015.

8 Usp. PETROVIĆ 1998.

9 MILČETIĆ 1911: 104 (Napomene, br. 4); MILČETIĆ 1955: 100-102. 
Regula franjevaca trećoredaca bila je prevedena i na talijanski jezik, ${ }^{14}$ ali taj prijevod sigurno nije izvornik hrvatskoga prijevoda. To se vidi već u nekoliko natuknica povjesnoga rječnika talijanskoga jezika:

KlZb1 14r6-8 I kada bude potribovanь k' voli vižitatura. - cum interpellatus ad Visitatoris extiterit voluntatem] Quando vocato et adomandato sirà, starà ala volemtade del visitatore (BATTAGLIA 2002: 923, s.v. Visitatore);

KlZb1 14v17-18 P'laĉe takoe i kad'meni. b'rez' široka ožd'riliě. ras'plaĉeni (... Fratres) - Clamydes quoque ac pelles absque scolaturis scissas] Li mantelli e le pelli dei frati sieno facti senza scolatura (BATTAGLIA 1996: 120, s.v. Scollatura ${ }^{1}$ ).

To postaje još zornije ako usporedimo tekst izdanja talijanskoga teksta s hrvatskim prijevodom:

Ni protivu nemu ludims s'min'emb. ne s'mii suprotiv'no poiti. Ako ovo g'do pokušati ras'činiti s'milı budet'. V' raz'sr'enie b(og)a v'semoguĉega. I b(la) ž(e)nihь ap(osto)lov' negovihь P(e)tra i P(a)vla GlZb 20r9-10 i b(la)ženiju ap(osto)lu (n)ego. Z(na) se da est' v'pal' v' grihь (K1Zb1 2316-22 = KlZb2 15v15-16r1, GlZb 20r5-10).

- Adonqua a neuno homo sia licito questa pagina de nostro statuto et de nostro ordenatione guastare et speçare, overo econtra essa per matto scutgiamento venire. E qualumque homo questo se scutigiasse de fare, esso emcorrarà et perverrà ella emdignatione dello onnipotente Deo et deli apostoli suoi Petro et Paulo (AGOSTINI 1978: 113).

Pretpostavlja se da je najmlađi prijepis Šimuna Glavića ovisan o jednoj verziji Šimuna Klimantovića. Tako Stjepan Ivančić navodi da je ,još za života Klementovića prepisa, takodjer glagolskim slovima u kvieru ali ne istim redom, sav njegov prvi obrednik fratar Šimun Glavić rodom iz Šibenika god. 1529. stanujući onda u samostanu sv. Pavla na Školiću Galevcu pred Zadrom“. ${ }^{15}$ Nadalje, Vjekoslav Štefanić piše da je Glaviću ,predložak za jedan dio građe mogao biti Klimantović, za drugi dio nije mogao biti (a to su odlomci o proštenjima i dr. do početka Plača), dok je kroniku mogao samo dopunjavati. Trebat će tačnije ispitati Glavićeve izvore“. ${ }^{16}$ Ivanka pak Petrović navodi da ,većina tekstova toga dijela knjige čine redovnički tekstovi, među kojima su Regula franjevaca trećoredaca sastavljena u 29 kapitula, Konstitucije (Kuštacioni) franjevaca trećoredaca iz 1492. u 38 kapitula, kojima je, s manjim razlikama, predložak bio Ritual Š. Klimantovića, Testament

\footnotetext{
14 Regola dell'ordine di Penitenza (prva pol. 14. st.; Biblioteca Nazionale Centrale Vittorio Emanuele di Roma, ms. Vittorio Emanuele 477; izdanje u AGOSTINI 1978: 101-113). Usp. također rukopise iz Nacionalne knjižnice u Napulju (Biblioteca Nazionale di Napoli) XII.F.4 (15.-16. st.) i XII.F.44 (15. st.); usp. CENCI 1971: 892 № 549, 910 № 572.

15 IVANČIĆ 1910: 133.

16 ŠTEFANIĆ 1970: 39.
} 
Sv. Franje te drugi franjevački redovnički obredni i poučni tekstovi ${ }^{\text {“ }} .{ }^{17}$ Svoj prilog završava sljedećim riječima: „Premda Glavićevi uzori u glagoljaškoj tradiciji još nisu temeljito istraženi, očito je da mu je glavni uzor bio Klimantović, veliki glagoljaški pisac, koji je svojim rukopisima u prvim dvama desetljećima XVI. st. dao temeljna djela franjevcima glagoljašima Dalmatinsko-istarske provincije, koja će poslije slijediti mnogi glagoljaški pisci i pisari“. ${ }^{18}$

Prije negoli se pozabavimo tekstologijom, ukratko ćemo nešto reći o jezičnoj karakteristici triju prijepisa. Pritom se oslanjamo ponajprije na prvi Klimantovićev zbornik jer se njegov drugi potpuno ili gotovo potpuno s njim slaže, dok je tekst Regule u Glavićevu zborniku dosta krnj.

Refleks starohrvatskoga jata slijedi do određene mjere pravilo Meyer - Yakubinsky, pri čemu ima dosta odstupanja. Postoje tri različita refleksa jata:

1. *ě > e: celo $(12 \mathrm{r} 20)$, vera $(12 \mathrm{v} 2)$, veré $(12 \mathrm{v} 11)$, po tes'noti $(12 \mathrm{v} 17)$;

2. *ě > i: rič'ju (12v9), k'rip'ko (12v13-14), s'tazi (12v15), jideniě (15v8; GlZb 12r16: édeniě), potribnimi (12v21-22);

3. iznimke pravilu Meyer - Yakubinsky: večnoga (12v18); Is'povidati (12v12), hotilb (12v14), cini (14v10).

Jaki je jer beziznimno prešao u a: katoličaske (12r4), va tmi (12r16), dragos 'tan (12v5), va (12v19). I slogotvorno $l \mathrm{u}$ Klimantovićevim rukopisima ima bezizniman refleks $u$, dok Glavić u nekoliko primjera zadržava stari refleks $l$ : obučet'se (13v12), isbpuniti (12v14-15), duž'ni (18r3-4; GlZb 14v20: dlžni), mučati (20r3; GlZb 17r5: mlčati), duž’ni (23r3-4). Osim toga, *v-ispred suglasnika ili ispred pauze ponekad je, ali ne i uvijek, prešlo u u-: uz'držet'se (15v10), uz'mak'net' (15v14), uzrokom' (16r20), uz'rokb (22v4). Intervokalni -ž- uvijek ima refleks -r-: nigdore (12v3), jurb (13r19), niš tare (15v4), morete (19r6), izrěni se (22v18). Isto tako je *dj prešao u $j$ bez iznimke: otrěenie (13v4), iz'viite (13v6), tuihb (13v8), raz'goeniem' (14v16), takoe (15r9), roeniě (16r22), prihaě (19r9), pohoeniě (21v2).

Nekoliko je primjera za prijelaz *ę u $a$ iza palatalnih suglasnika: priěmši (13r1), p'riětiě (13r5), počalnika (15r19), a jedan jedini primjer ima za prijelaz a u $e$ iza $r$ : res'teniju $(12 \mathrm{v} 23)$.

U morfologiji u Klimantovićima prijepisima regule uočava se gotovo isključivo postojanje nastavka -om u instrumentalu jednine ženskih -(j)a-osnova, s čime se ne uvijek podudara jezik Šimuna Glavića (ovdje prevladava stariji nastavak -oju): rukomb (14r10), sobom' (17r17; = GlZb 14r9), jut(a)rnom'(17v12; GlZb 14v7: |nju), nevolom' (18v20; = GlZb 15v16), sobom' (22r14; GlZb 19r9: soboju), pravdomb (22r18; = GlZb 19r12), bratijom' (22r23; GlZb 19r16: bratiom).

17 PETROVIĆ 1998: 732.

18 Isto: 733. 
Kod lokativa jednine muškoga i srednjega roda postoji kolebanje između nastavaka - $i$ i -u, koji se sreću jednako često: všastiju (14r13), jideniju (16r13), v'lizeniju (18r16), nemiru (18v1), listu (19v2), gradu (20v3); stan'ii (14r15), godici i (17r8-9), deli (18v5), govorenii (19r5), govorěnii (19r9-10), mes 'ti (20v3), s'provoenii (20v5), od'šastii (20v13), mesti (21v6), ud'ržanii (22v1). Upada u oči to što u mekih -ij-osnova nikada nema stezanja, već se uvijek pojavljuje nekontrahirani nastavak - $i$.

Konačno, usporedba rukopisa pokazuje da se obje inačice Šimuna Klimantovića često potpuno slažu u ortografiji i fonetici pojedinačnih riječi, a da se veće razlike uočavaju između mlađega prijepisa Šimuna Glavića i Klimantovićevih rukopisa:

KlZb1 12v6 Ø] = KlZb2 4v7-8] GlZb 9r5-7 ...pasnie (stazu) pripravl...ž.stva věčnoga plaĉe ... e ob...vaet - Haec est, quae salutis semitam praeparat, \& felicitatis aeternae praemia, gaudiaque pollicetur.

KlZb1 14r:4 sag'rišeniě] = K1Zb2 5r11] GlZb 10v15 prigriševaniě - transgressionibus

K1Zb1 14r10 rukomb] = K1Zb2 5r16] GlZb 10v19 po ruci - per manum

K1Zb1 14r11 napiše] GlZb 10v20 upiše - redigatur

KlZb1 14r21 da ne mozi] = K1Zb2 5v6] GlZb 11r9 da ne more - ut ... valeat

K1Zb1 15r15 b'rezb v'sakihs s'vilb] GlZb 12r1 brezb svil kih godi - absque serico ullo

K1Zb1 15v5 s'voim' domaĉim'] = K1Zb2 6v15] GlZb 12r13-14 svoimb hižanom's - a propria familia

KlZb1 16r1 jisti] GlZb 12v11 priěti - sumere

KlZb1 16r1-2 od' prestavleniě nihova] = KlZb2 7r15] GlZb 12v12 nihь - de appositis ab eisdem

K1Zb1 16r7 Začb] = K1Zb2 7r20] GlZb 12v16 ere - cum

$\mathrm{K} 1 Z \mathrm{~b} 1$ 16v16 ki su noseĉe] $=\mathrm{KlZb} 28 \mathrm{r} 14$ (ke)] GlZb 13v4 tegotne - gravidae

KlZb1 20r9 nemoĉnih'] = KlZb2 12r15 nemoĉ'nikovb] GlZb 17r10 nemoĉnihь - infirmis

K1Zb1 20r15-16 I nega pečal'no naučite k' priětiju pokaěniě] GlZb 17r15-16 I toga pečalno k' priětiju pokaěniě učeĉe - ipsum sollicite ad recipiendum poenitentiam ... inducentes

K1Zb1 20v12 Toga ciĉb] K1Zb2 12v19 Toga ciĉa] GlZb 17v11-12 Togo radi - Praeterea

K1Zb1 21v25-22r1 ovoga reda] K1Zb2 $14 r 16$ ovoga rěda] GlZb 18v18 sego čina - hujusmodi

K1Zb1 22r3-4 ednuč' v' godiĉe s'vršuite] = K1Zb2 14r19 (godicii)] GlZb 19r1 ednom' v' lěti svršui se - semel exerceatur in anno

KlZb1 22r4 Nego] = KlZb2 14r20] GlZb 19r1 razvi

KlZb1 23r1 toga t'ret(o)ga rěda] $=\mathrm{KlZb2]} \mathrm{GlZb} \mathrm{19v13} \mathrm{vašega} \mathrm{reda}-$ vestri Ordinis 
K1Zb1 23r4 ili od' pos'tavlenih' ] = K1Zb2 15v1-2] GlZb 19v15 ili postavleni - vel statutis

KlZb1 23r20-21 I b(la)ž(e)nihь ap(osto)lov' negovihь P(e)tra i P(a)vla] = KlZb2 15v19-20] GlZb 20r9-10 I b(la)ženiju ap(osto)lu (n)ego.

Kod nekih varijantnih čitanja nije moguće odrediti tko ima prvobitnu verziju, Klimantović ili Glavić. Ipak, u mnogobrojnim primjerima Glavićev se tekst podudara s latinskim izvornikom. Time se dokazuje da je Glavić, za razliku od Klimantovića, sačuvao izvorni tekst, što je u proturječju s prevladavajućim mišljenjem u znanstvenoj literaturi. Ova je činjenica važna ne samo za pitanje prevoditelja, a očigledno je da prijevod Regule franjevaca trećoredaca nije napravio Šimun Klimantović, već je itekako važna za pitanje vremena nastanka ovoga prijevoda.

Prijevod se odlikuje nizom dodataka, odnosno dopuna. Između njih ima takvih koje se, prema podudarnom svjedočanstvu triju rukopisa, mogu pripisati prevoditelju, ali i takvih koje su posljedica Klimantovićeve redakcije. Valja naglasiti da je već prevoditelj imao sklonost prema raznolikosti izražavanja, prema copia verborum:

K1Zb1 I ako ona obeĉ(a)jut' se k'rip 'ko ud'ržati. I pravo verovati. (13r:8-10)] GlZb 9v14 e kripko - \& si eas professi fuerint, vereque crediderint

KlZb1 da prikažet' se ča se naibr'že morě. na kaš'tiganie is'katelemь eretiča(sk) oga lukav'stviě. To e(stb) in 'kvi(ž)ituru. (13r19-23)] GlZb 10r7-9 na nakazanie iskatelemb eretičaskoga lukavs'tviě. to e(stb) inkvizituru - assignetur ille quamcitius Inquisitoribus pravitatis haereticae puniendus.

KlZb1 nega čins i s'tanie vlazeĉumu. pečal'no iz'viite. (13v4-6)] GlZb 10r14 vlazeĉu - ejus officium statum \& conditionem solerter exploren

KlZb1 (tuihь vraĉenie.) i zadovole učinenie (13v8-9)] GlZb Ø - alienorum restitutionem

KlZb1 kad' meni. b'rez' široka ožd'riliě. ras'plaĉeni (14v17-18)] GlZb 11v4-5 ... široka oždriliě - pelles absque scolaturis scissas

K1Zb1 moš’ne odb kože usaniě (15r11-12)] GlZb 11v20 mošne kožne - bursas de corio

KlZb1 m(o)litvu go(spod)sku. To e(stb) o(tь)čen(a)šb. (19r12-13)] GlZb 16r11 to e(stb) o(tb)čen(a)šb - Orationem Dominicam

KlZb1 va veki dokolě e živ'. (21r22-23)] GlZb 18 r17 do života - ad vitam

KlZb1 Ako li se ne potaret' (22r17-18; cf. 22r17: da potaret' se)] GlZb 19r11 ako li ne - alioquin

KlZb1 ki ne bude hotilı pobolšati. to e(stb) pokoriti se (22v11-12) - incorrigibilis

KlZb1 po tretom' s'viceniju. i pokaraniju. i kaš'tiganiju (22v12-14) - post trinae admonitionis instantiam.

Najčešće je prijevod dobar; prevoditelj je dobro razumio latinski tekst $i$ izabrao je odgovarajuće izraze, koliko možemo to danas prosuditi. On za identične latinske konstrukcije - na primjer, za apsolutni ablativ ili za gerundive - bira različite mogućnosti prijevoda, ne slijedeći izvornik ropski: 
Konkretizacija:

K1Zb1 v' nihovihь v'lastitih' domih' (15v23) - in eorum Conventualibus domibus

K1Zb1 bulam' (18v8) - privilegia

KlZb1 v listu (19r2) - in contractu

K1Zb1 A oni ki nisu k'nižnici. ki ne umiju k'nigu (20v20-21)] GlZb 17v18-19 A ki nisu knižnici - illiterati

KlZb1 ki ne bude hotilb pobolšati (22v11-12) - incorrigibilis.

Jednostavnije izražavanje:

K1Zb1 Putujucim' (15v14-15) - itinere constitutis

K1Zb1 teže (17r1) - exercitio laboris incumbent

KlZb1 usilovani buduts (18v10-11) - vexationibus impetantur

KlZb1 u veliki govorěnii (19r9-10) - in multiloquio

K1Zb1 ukazali budu (19v1) - curaverint intimare.

Idiomatsko izražavanje:

KlZb1 odb ovoga s'vita prestavit' se (20r23-20v1) - de praesenti luce migraverit

KlZb1 s'tanovit' rokb dos'tig'ni (21v1) - certum tempus comprehendat.

Latinske gerundive prevodi i infinitivom i glagolskim imenicama:

K1Zb1 kih na s'hranenie ovoga žitiě ob'raz' v'zeti se prigoditb. (13r2-4) - quos ad observandam hujusmodi vitae formam assume contigerit

KlZb1 Da čuvaite se. sa v'simь timb pečal'no. Da niki eretik' ... da se ne pripus'titb. (13r12-18) - Praecavendum est tamen sollicite, ne quis haereticus ... admittatur.

KlZb1 da prikažet' se ča se naibr'že morě. na kaš'tiganie is'katelemb eretiča(sk) oga lukav'stviě. To e(stb) in'kvi(ž)ituru. (13r19-23)] GlZb 10r7-9 na nakazanie iskatelemь eretičaskoga lukavst'iě. to e(stb) inkvizituru - assignetur ille quamcitius Inquisitoribus pravitatis haereticae puniendus.

KlZb1 Ili od'ložeĉi prazd'nika roeniě g(ospod)na n(a)š(e)ga Is(u)h(rbst)a. Ako se prigodi v' petaks s'lužiti. (16r21-23) - vel nisi festum Natalis Domini feria ipsa occurreret observandum

KlZb1 A od' čineniě mira meju bratiomb. i sestramb (!). I oĉe takoe i meju (18v) z'van'nimi. v' nemiru buduĉim'. (18r22-18v1) - De pace vero inter Fratres, $\&$ Sorores, aut etiam exteros in Discordia positos facienda

K1Zb1 Ki nih' h' kaěniju i k' m(i)losrdiju delomb s'vrševati opominai. (19v2320r1) - qui eos ad poenitentiam, \& misericordiae opera exercenda hortetur

K1Zb1 Nego ako za nevolju i za pot'ribu z'godi im' se. veĉe kratb. učiniti. (22r4-6) - nisi necessitate aliqua suadente fuerit (scil. visitatio) pluries facienda.

KlZb1 Minis'tri očite k'rivine bratie i ses'tarb. Na kaš'tiganie pohoditelju navis'tite. (22v7-10) - Ministri vero manifestas Fratrum, \& Sororum culpas Visitatori denuncient puniendas 
KlZb1 I odb druž'be b'ratar'stva toga izrěni se. I potom' toga va toi skupĉini da se ne naidetb. $(22 \mathrm{v} 17-20)]$ GlZb - de Fraternitatis consortio abjiciendus ab ipso, \& in Congregatione postmodum publicandus.

Istina, sreću se gdjegdje primjeri manje uspjeloga prijevoda, pri čemu se ne može uvijek isključiti da ne potječu od prvobitnoga prijevoda, već od Klimantovićeve redakcije. Nažalost, na nekim je mjestima tekst Glavićeva zbornika nestao (rukopis ima cijeli niz rupa) ili se jedva može čitati te se zbog toga ne može do kraja rekonstruirati izvorni prijevod:

KlZb1 put' pres'tupleniě rič'ju g(ospod)inomь (... ukazue) (12v8-10) - viam ascendendi ad Dominum verbo (... demonstrans)

KlZb1 priěmši (13r1) - intendentes

KlZb1 (kad'meni. ...) I za v'se za to ne ob'lačite se. kako se prik'lada giz'daniju $(14 \mathrm{v} 19-21)$ - (pelles ...) affibulatas tamen, vel patulas, ut congruit honestati K1Zb1 p'laĉemb da ob'lačet' se. ot' smerěna suk'na učinenь (14v23-15r1) clamyde inducantur, \& tunica de hujusmodi humili panno factis

KlZb1 od'vrgši vsa ina. ... Taĉin'nimb ovoga s'vita urěšeniemb. (15r18-22) depositis ceteris ... vanis hujus saeculi ornamentis

KlZb1 I ocee takoe i meju z'van'nimi. v' nemiru buduĉim'. (18r23-18v1) - aut etiam exteros in Discordia positos

KlZb1 u takovih se ud'ržite (18v15-16) - in tabulis processuri.

U leksiku ima dosta posuđenica iz latinskoga i talijanskoga jezika, učestalih i rijetkih, na primjer: biskups (18v4, 18v11-12), bula (18v8), eretičbskb (K1Zb1 13r21, 13r21-22), eretičbstvo (K1Zb1 13r14-15), eretikb (KlZb1 13r13, 13r16), furtuna (K1Zb1 12r23-12v1) 'tempestas', fuštanb (15r2-3, 15r4) 'guarnellum (placentinum)', 'paludellum', grišpanie (15r6) 'crispatura', inkvižiturb (13r2223), kadmenь (14v17) 'pellis', 'pellitio', kaštiganie (13r20-21, 22v8-9, 22v13-14), katoličbskb (KlZb1 12r14, 13r5-6), korizma (18r5, 18r6), kumplita $(17 \mathrm{v} 4,17 \mathrm{v} 20-$ 21), kuštodb (21v19-20), mankati (21v8), ministrb (13v3, 14r12, 14v15, 17r22, 18v11, 21r21, 21v3), ministrbstvo (21r13, 21r23), misa (19r17, 19r21), munita (19v5), nona (17v3-4), oficii (18r1), prěma $(17 \mathrm{v} 3,17 \mathrm{v} 6,17 \mathrm{v} 20)$, psalbmb $(17 \mathrm{v} 9$, 17v21-22, 20v20), regula (12r1-2, 23r12), saltirb (17v6, 20v20), šeksta (17v3), tanbcb (15v1), tastamentb (18r11, 18r14, 18r19-20), terca (17v3), unestb (15r22), vardiěnb (21v20), vižitaturb (14r7-8, 14v14). Neki se rabe i tamo gdje u tekstu izvornika nema za to povoda, na primjer: bula 'privilegium', furtuna 'tempestas', fuštans 'guarnellum (placentinum), paludellum', kadmens 'pellis, pellitio'. Neke su nastale tek u sekundarnoj redakciji Klimantovića (npr. unestb). Od ovih posuđenica u hrvatskoj redakciji crkvenoslavenskoga jezika sljedeće nisu potvrđene ${ }^{19}$ :

19 U kartoteci Staroslavenskoga instituta 17. rujna 2014. imao sam mogućnost provjeriti neke riječi kojih nema u publiciranim sveščićima Rječnika (RCJHR), na čemu zahvaljujem ravnateljstvu instituta i suradnicima Rječnika. 
bula, furtuna, fuštanb, inkvižiturb, kadmenb, kuštodb, ministrbstvo, tastamentb, unestb, vižitaturb. Nekoliko ih ima Akademijin rječnik: bula $a^{20}$, furtuna ${ }^{21}$, fuštan ${ }^{22}$, inkvižitur ${ }^{23}$, kadmen $^{24}$, kuštod $^{25}$, unest ${ }^{26}$, vižitatur $^{27}$.

Od domaćih, odnosno neposuđenih riječi nekoliko ih je koje nisu zasvjedočene u Rječniku crkvenoslavenskoga jezika hrvatske redakcije28: ĉudb (14r14) 'conditio', dobrostivbnb (12v23-13r1) 'benignus', dragostbnb (12v5) 'gratiosus', gluтьсь (15v3) 'histrio', vbzmbknuti (15v14) 'subtrahere', nerazvlačito $(18 \mathrm{r} 16$, 20v14) 'immediate', nezavětovanb (18r16) 'intestatus', otetie (17r19, 17r20-21) 'defensio' 29 , oždrělie (14v18) 'scol(1)atura', povezača $(15 \mathrm{r} 11)$ 'binda', razgoenie (14v16) 'dispensatus', svoita (18r7) 'parrochia'30, usnie (15r14), vbzmsknuti $(15 \mathrm{v} 14)$ 'subtrahere'. Neke su opet oprimjerene u Akademijinu rječniku, na primjer: ćud ${ }^{31}$, glumac ${ }^{32}$, oždrijelje $e^{33}$, povezača ${ }^{34}$, razgođenje $e^{35}$, svojta ${ }^{36}$, usanje $^{37}$, uzmaknuti ${ }^{38}$.

Osim toga, u Reguli se sreću rjeđi leksemi, posuđenice i domaće riječi, koje već postoje u starijim hrvatskoglagoljskim tekstovima: dobitie ${ }^{39}$, vardiěn ${ }^{40}$. Djelomično se to potvrđuje i s pridjevom dobrostivbnb, koji dolazi bez sufiksa -bn-, u značenju dobrostivb, koji je zasvjedočen u pariškom Borislavićevu zborniku iz 1375. godine. ${ }^{41}$ Zanimljivo se semantičko podudaranje sa starijim hrvatskogla-

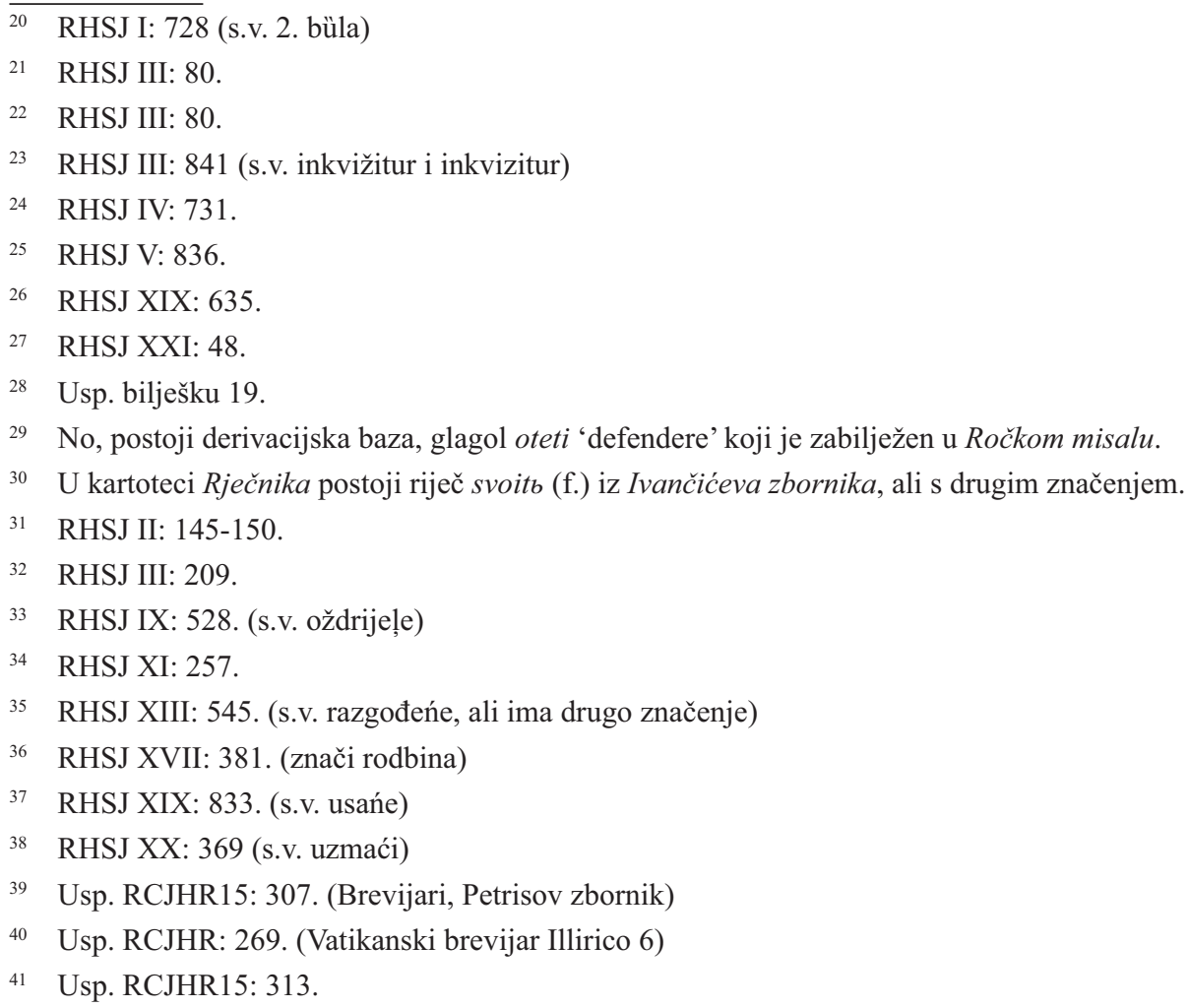


goljskim tekstovima (npr. s hrvatskoglagoljskim misalom) zapaža u riječi red (i njezinim derivatima) sa značenjem 'religio; religija, vjera'.

Nekih riječi nema u građi Rječnika crkvenoslavenskoga jezika hrvatske redakcije, a prema svjedočanstvu Akademijina rječnika zasvjedočene su u starijem hrvatskom jeziku. To se odnosi na netom spomenute dragostbnb, glumbcb i vbzmbknuti. S druge strane, neke su riječi u franjevačkoj reguli zasvjedočene ranije ili mnogo ranije negoli u tekstovima ekscerpiranim u Akademijinu rječniku, na primjer fuštans i oždrělie.

Posebno je zanimljiva riječ kadmen 'krzneni kaputić' (K1Zb1 14v17). Ona je u Akademijinu rječniku citirana jednim jedinim primjerom iz rječnika Fausta Vrančića koji ju je naveo u spisu Vocabula dalmatica quae Ungari sibi usurparunt, usporedivši je s mađarskom riječi „keüdmen“. Danas se najčešće smatra mađ. ködmön izvorom hrvatske riječi. U mađarskome se tumači kao posuđenica iz predosmanlijskoga turkijskog jezika, iako točnih usporedica nema (pretpostavlja se da je posrijedi izvedenica iz glagola *käd- 'obući'). Problem svakako predstavlja fonetska razlika između hrvatske i mađarske riječi.

Nema sumnje da je hrvatska trećoredska regula važan i dosad neiskorišteni izvor za leksikologiju starijega hrvatskog jezika. Drugo je pitanje kada je nastao prijevod. Terminus post quem predstavlja bula pape Nikole IV. iz 1289. godine. Terminus post quem non, najstariji je prijepis, onaj Klimantovićev koji je nastao između 1501. i 1512. godine. Budući da prijepis Šimuna Glavića nije ovisan o tekstovima Šimuna Klimantovića, prijevod je morao nastati prije najstarijega prijepisa. Je li tako prijevod mogao nastati 1430. ? Ta je, naime, godina navedena u dva Klimantićeva rukopisa: Dana bi v'rěti na letb božihb tekuĉihb .č. $(=1000)$ i.u. $(=400) i . \hat{j} .(=30)$ Peti na des(e)te d(a)no miseca sek'teb'ra. d'rugo léto našega bis'kups 'tva (K1Zb2 16r1-5). Ova je informacija istovjetna s bulom Nikole IV.: Datum Reate XVI. (vl.: XV.) Septembris, Pontificatus nostri Anno Secundo. U Glavićevu prijepisu nema godine. ${ }^{42}$ Štefanić to objašnjava ovako: „U Klimantovića slijedi iza Rieti: Na lět’ bžihb 1430, što je Glavić slučajno ispustio“. ${ }^{43}$ Budući da je Glavićeva verzija izvornija od Klimantovićeve, možemo pretpostaviti da je posrijedi Klimantovićev dodatak. Možda je pobrkao, kako je mislio Štefanić, izdavanje Regule za franjevce trećoredce s potvrđivanjem Konstitucija za Malu braću, što je papa Martin V. učinio 15. lipnja 1430. Jezične značajke starohrvatskoga teksta nisu u proturječnosti s datiranjem prijevoda u prvu polovicu XV. ili oko sredine ovoga stoljeća.

$\overline{42}$ ŠTEFANIĆ 1970: 36. Tamo kolofon glasi ovako: „Dana bi(stb) v rieti. .dï. (= 15) d(a)nь miseca sektebra drugo 1(e)to n(a)š(e)ga biskupstva ti že g(ospod)i p(o)m(i)lui n(a)sb. A gdo sliši ovu rěgulu ima prošceniě ot grihov svoihь .ï.g. $(=24)$ krat po .k. $(=40)$ danь moĉiju i milostiju boga vsemoguĉega. ti že g(ospod)i pomitui (!) nas b(og)u hvali“ (20r11-19).

43 ŠTEFANIĆ 1970: 39, bilj. 2. 
Naknadno su provjerena sva mjesta u Glavićevu zborniku de visu koja se nisu mogla pročitati u kopiji. U budućim bi istraživanjima trebalo pregledati sve latinske i talijanske rukopise koji donose trećoredsku Regulu. Zasad nisam naišao na latinski rukopis gdje bi zajedno bile Regula trećoredaca i Oporuka sv. Franje jer se u svim trima hrvatskim prijepisima oba teksta čitaju zajedno. Učinjena je također usporedba leksika starohrvatskoga prijevoda s nepubliciranom građom hrvatsko-crkvenoslavenskoga rječnika.

Kao zaključci provedenoga istraživanja Regule proizlaze sljedeće konstacije:

(1) Prijevod Regule, za razliku od dosadašnjega mišljenja, nije napravio Šimun Klimantović;

(2) Prijevod najbliži latinskomu izvorniku sačuvao se najbolje u rukopisu Šimuna Glavića;

(3) Šimun Klimantović izvršio je razmjerno dalekosežnu jezičnu i tekstološku redakciju zasvjedočanu u oba njegova prijepisa;

(4) Prijevod je vjerojatno nastao u 15. stoljeću, možda već u prvoj polovici ili oko sredine ovoga stoljeća;

(5)Po svoj prilici istodobno je s Regulom prevedena i Oporuka sv. Franje.

Bibliografija

\section{Kratice}

A-PFT $=$ Arhiv Provincijalata franjevaca trećoredaca u Zagrebu

GlZb = Zbornik Šimuna Glavića (1529-1557; Arhiv HAZU, Ia25)

$\mathrm{K} 1 Z \mathrm{~b} 1=$ Zbornik Šimuna Klimantovića $(1501-1512 ; \mathrm{A}-\mathrm{PFT})$

K1Zb2 = Zbornik Šimuna Klimantovića u Berčićevoj zbirci u Petrogradu (1509; br. 2).

\section{Literatura}

AGOSTINI, Francesco. 1978. Testi trecenteschi di Città di Castello e del contado. Firenze: Accademia della Crusca.

BATTA GLIA, Salvatore. 1972. Grande dizionario della lingua italiana. VI (Fio - Grau). Torino: Unione Tipografico-Editrice Torinese.

BATTAGLIA, Salvatore. 1984. Grande dizionario della lingua italiana. XII (Orod Pere). Torino: Unione Tipografico-Editrice Torinese.

BATTAGLIA, Salvatore. 1986. Grande dizionario della lingua italiana. XIII (Perf-Po). Torino: Unione Tipografico-Editrice Torinese.

BATTAGLIA, Salvatore. 1996. Grande dizionario della lingua italiana. XVIII (SchoSik). Torino: Unione Tipografico-Editrice Torinese.

BATTAGLIA, Salvatore. 2002. Grande dizionario della lingua italiana. XXI. Torino: Unione Tipografico-Editrice Torinese 
BULLARIUM 1768 = Bullarium Franciscanum Romanorum Pontificum Constitutiones, epistulas ac diplomata continens tribus ordinibus Minorum, Clarissarum, et Poenitentium a Seraphico Patriarcha Sancto Francisco institutis concessa ab illorum exordio ad nostra usque tempora iussu atque auspiciis reverendissimi patris magistri Fr. Dominici Andreae Rossi de Pisauro artium, et sacrae theologiae doctoris et Minorum Conventualium ministri generalis conquisitis undique monumentis nunc primum in lucem editum notis, atque indicibus locupletatum. Tomus IV. (Referens ea quae Nicolai IIII, Caelestini V et Bonifacii VIII sunt). Romae: Typis Sacrae congregationis de propaganda fide, MDCCLXVIII.

CENCI, Cesare. 1971. Manoscritti francescani della Biblioteca Nazionale di Napoli. Vol. II. Grottaferrata: Editiones Collegii S. Bonaventurae ad Claras Aquas.

CENCI, Cesare. 1981. Bibliotheca manoscripta ad sacrum conventum Assisiensium. Vol. I + II. Assisi: Casa Ed. Francescana.

ČRNČIĆ, Ivan. 1867. Najstarija poviest krčkoj, osorskoj, rabskoj, senjskoj i krbavskoj biskupiji. U Rimu: Slova vjeroplodničina u ruku viteza Petra Mariettia.

ESSER, Kajetan. 1949. Das Testament des heiligen Franziskus von Assisi. Eine Untersuchung über seine Echtheit und seine Bedeutung. Münster/Westfalen: Aschendorffsche Verlagsbuchhandlung.

ESSER, Kajetan (Hrsg.). 1976. Die Opuscula des hl. Franziskus von Assisi. Grottaferrata: Editiones Collegii S. Bonaventurae ad Claras Aquas.

IVANČIĆ, Stjepan. 1910. Povjestne crte o samostanskom III Redu sv. O. Franje po Dalmaciji, Kvarneru i Istri i poraba glagoljice u istoj redodržavi. Sa prilozima. Zadar: Tiskarna E. Vitaliani.

MEERSSEMAN, Gilles Gérard. 1982. Dossier de l'Ordre de la Pénitence au XIIIe siècle. Fribourg: Éditions Universitaires.

MILČETIĆ, Ivan. 1911. Hrvatska glagoḷska bibliografija. I. Dio. Opisi rukopisâ. Starine 33: I-XIV + 1-505.

MILČETIĆ, Ivan (†). 1955. Berčićeva zbirka glagoljskih rukopisa i štampanih knjiga u Lenjingradu. Radovi Staroslavenskog instituta: 293-128 (+ 10 sl.).

NAZOR, Anica. 1993. Čučković, Andrija. Hrvatski biografski leksikon. 3 (Č-Đ). Zagreb: Leksikografski zavod Miroslav Krleža, 115.

PETROVIĆ, Ivanka. 1998. Glavić, Šimun. Hrvatski biografski leksikon. 4 (E - Gm). Zagreb: Leksikografski zavod Miroslav Krleža, 732-733.

PETROVIĆ, Ivanka. 2009. Klimantović, Šimun, Hrvatski biografski leksikon. 7 (Kam - Ko). Zagreb: Leksikografski Zavod Miroslav Krleža, 381-382.

RHSJ =Rječnik hrvatskoga ili srpskogajezika. I-XXIII. Zagreb: Jugoslavenska akademija znanosti i umjetnosti, 1880-1975.

RCJHR = Rječnik crkvenoslavenskoga jezika hrvatske redakcije. I. svezak ( $\mathrm{a}^{1}-\mathrm{vrêd}$ ). ur. Anica Nazor. Zagreb: Staroslavenski institut, 2000.

RCJHR15 = Rječnik crkvenoslavenskoga jezika hrvatske redakcije. 15. sveščić (danb ${ }^{1}$ dovolnê). ur. Anica Nazor. Zagreb: Staroslavenski institut, 2008. 
RUNJE, Petar. 2012. Prema izvorima II. Rasprave i članci o hrvatskim franjevcima trećoredcima glagoljašima. ur. Tomislav Galović. Zagreb: Povijesno društvo otoka Krka i Provincijalat franjevaca trećoredaca glagoljaša.

RUNJE, Petar. 2015. Fra Šimun Klimantović u svom vremenu. Ogulin: Ogranak Matice hrvatske.

SRDOČ-KONESTRA, Ines - LAJŠIĆ, Saša. 2008. Fra Šimun Klimantović (...), ni pisac ni pod piscem pisac, Fluminensia 20/1: 75-95.

ŠTEFANIĆ, Vjekoslav. 1956. Glagoljaši u Kopru, god. 1467-1806. Starine JAZU 46: 203-329.

ŠTEFANIĆ, Vjekoslav. 1970. Glagoljski rukopisi Jugoslavenske akademije. Sv. 2. ZagrebJugoslavenska Akademija zbanosti i umjetnosti.

ŠTRKALJ-DESPOT, Kristina. 2010. Srednjovjekovna ars memoria i Šimun Klimantović. Zadarska smotra 59/1-2: 79-99.

TEMPERINI, Lino. 1991. Testi e documenti sul Terzo ordine francescano (sec. XIII-XV). Originale latino e versione italiana. Roma: Editrice Franciscanum.

\section{Die Regel der Franziskaner des 3. Ordens in altkroatischer Übersetzung}

Die Franziskanerregel des 3. Ordens wurde am 18. August 1289 von Papst Nikolaus IV. erlassen (Inc.Supra montem Catholicae Fidei). Der lateinische Text der Regel wurde auch in die altkroatische Sprache übersetzt. Die kroatische Version liegt in drei frühneuzeitlichen Handschriften in glagolitischer Schrift vor. Die zwei ältesten sind Sammelbände des Šimun Klimantović aus den Jahren 1501-1512 (Klimantović-Sammelband, Kloster der Franziskaner des 3. Ordens „Hl. Xaver” in Zagreb) und 1509 (Russische Nationalbibliothek in St. Petersburg, Berčić-Sammlung, Nr. 2). Eine weitere Abschrift findet sich im Sammelband des Šimun Glavić (Archiv der Kroatischen Akademie der Wissenschaften und Künste in Zagreb, HAZU Ia25, 1529-1557).

Im Artikel wird die Sprache der drei Abschriften untersucht, primär anhand des Sammelbands von Klimantović aus den Jahren 1501-1512. Diese Handschrift wendet im Großen und Ganzen konsequent die Regel der Vertretung des Jat-Lautes nach Meyer-Jakubinskij an. Das intervokalische -ž- ist ausnahmslos zu - $r$ - geworden, die Lauverbindung * $d j$ hat sich ausnahmslos zu $j$ entwickelt, das silbische $l$ hat ausnahmslos $u$ ergeben. In der Morphologie herrscht im Instrumental Singular der Feminina ohne Ausnahme die Endung -om, während sich im Lokativ Singular der Maskulina die Endungen $-i$ und $-u$ abwechseln. Im Sammelband des Šimun Glavić, in dem die Franziskanerregel auf Grund von äußerer Einwirkung (vor allem Löcher und schwarze Stellen) nicht vollständig erhalten ist, sind teilweise ältere Formen vorhanden (z.B. was das silbische $l$ oder den Instrumental Singular der Feminina betrifft). 
Im Wortschatz begegnet man etlichen Lexemen, die im Kroatischen entweder bisher viel später belegt waren bzw. die außerhalb der Franziskanerregel des 3 . Ordens überhaupt nicht bekannt sind. Dies betrifft vor allem seltene Entlehnungen aus dem Italienischen. Der Übersetzungsstil der altkroatischen Franziskanerregel des 3. Ordens ist durch Zusätze, Konkretisierung und Vereinfachung mancher lateinischer Ausdrücke charakterisiert, in Einzelfällen kann man aber auch idiomatische Ausdrücke beobachten.

Die textologische Untersuchung der drei Abschriften hat zu der bisher unbekannten Schlussfolgerung geführt, dass die jüngste Handschrift, diejenige des Šimun Glavić, den ursprünglichsten Texttypus repräsentiert, und dass Šimun Klimantović den Text sprachlich und stilistisch redigierte.

Diese textologische Tatsache führt auch zur Neubewertung der Abfassungszeit der Übersetzung. Sie ist wahrscheinlich in der ersten Hälfte oder um die Mitte des 15. Jahrhunderts entstanden. Die Angabe des Kolophons von Klimantović „im Jahre 1430" (für das lateinische Original!), die bei Glavić fehlt, beruht wohl, wie bereits von Vjekoslav Štefanić vermutet, auf der Verwechslung mit der Bestätigung der Konstitutionen des Minoritenordens durch Papst Martin V. vom 15. Juni 1430.

\section{The Rule of the Third Order Franciscans in Old Croatian translation}

The rule of the Third Order Franciscans was issued on August 18, 1289 by Pope Nicholas IV. Adopted (Inc.: Supra montem Catholicae Fidei). The Latin text of the Rule was also translated into the old Croatian language. The Croatian version exists in the Glagolitic script in three early modern manuscripts. The two oldest are the miscellany of Šimun Klimantović from 1501 - 1512 (Klimantović's miscellany, the monastery of the Third Order Franciscans „St. Xavier“ in Zagreb) and 1509 (National Library of Russia in St. Petersburg, Berčić Collection, No. 2). Another copy is in the miscellany of Šimun Glavić (Archives of the Croatian Academy of Sciences and Arts in Zagreb, HAZU Ia25, 1529 - 1557).

This paper examines the language of the three copies, primarily on the basis of the Klimantović's miscellany from $1501-1512$. Generally, this manuscript consistently follows the rule of Meyer-Jakubinskij on the development of sound jat. The intervocalic - $\check{z}$ - invariably became $-r$-, the cluster * $d j$ invariably became $j$, the syllabic $l$ invariably gave $u$. In morphology the ending -om in the feminine instrumental singular has no exception. In the miscellany of Šimun Glavić, in which the Franciscan rule has not been fully preserved due to external influences (especially holes and black spots), partially older forms are present (for example with regard to the syllabic $l$ or feminine instrumental singular). 
In the vocabulary several lexemes are present that have been previously attested in the Croatian language either much later or are completely unknown outside the Rule of the Third Order Franciscans. This applies particularly to rare loans from the Italian language. The translation of the old Croatian Rule of the Third Order Franciscans is characterized by additions, concretization and simplification of many Latin expressions, but in individual cases one can also observe idiomatic expressions.

The textological investigation of the three copies has led to the surprising conclusion that the youngest manuscript, that of Šimun Glavić, represents the original text, and that Šimun Klimantović edited the text linguistically and stylistically.

This textological fact has also led to a reevaluation of the date when the translation was composed. It probably originated in the first half or the middle of the $15^{\text {th }}$ century. Klimantović's colophon entry ,in 1430“ (for the Latin original!), which is absent in the Glavić's copy, is probably based on the confusion with the confirmation of the Constitutions of the Minorite Order by Pope Martin V on June 15,1430 , as has been already suggested by Vjekoslav Štefanić.

Schlüsselwörter: Franziskanerregel des 3. Ordens, altkroatische Sprache, Šimun Klimantović, Šimun Glavić

Keywords: Rule of the Third Order Franciscans, old Croatian language, Šimun Klimantović, Šimun Glavić

Ključne riječi: regula franjevačkoga Trećeg reda, starohrvatski jezik, Šimun Klimantović, Šimun Glavić

Johannes Reinhart Universität Wien, Institut für Slawistik A-1090 Wien, Spitalgasse 2, Hol 3 johannes.reinhart@univie.ac.at 


\section{FILOZOFSKI FAKULTET SVEUČILIŠTA U ZAGREBU \\ ZAVOD ZA HRVATSKU POVIJEST \\ INSTITUTE OF CROATIAN HISTORY \\ INSTITUT FÜR KROATISCHE GESCHICHTE}
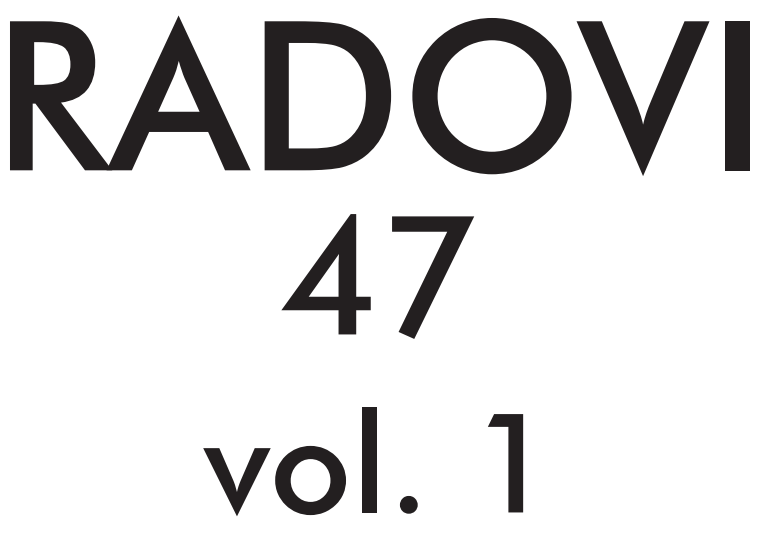

ZAVOD ZA HRVATSKU POVIJEST

FILOZOFSKOGA FAKULTETA SVEUČILIŠTA U ZAGREBU

\section{PF press \\ ZAGREB 2015.}




\title{
RADOVI ZAVODA ZA HRVATSKU POVIJEST FILOZOFSKOGA FAKULTETA SVEUČILIŠTA U ZAGREBU
}

\author{
Knjiga 47, vol. 1
}

\author{
Izdavač / Publisher \\ Zavod za hrvatsku povijest \\ Filozofskoga fakulteta Sveučilišta u Zagrebu \\ FF-press \\ Za izdavača / For Publisher \\ Vlatko Previšić \\ Glavni urednik / Editor-in-Chief \\ Hrvoje Gračanin \\ Izvršna urednica / Executive Editor \\ Inga Vilogorac Brčić \\ Uredništvo / Editorial Board
}

Bruna Kuntić-Makvić (stara povijest/ancient history), Zrinka Nikolić Jakus (srednji vijek/ medieval history), Hrvoje Petrić (rani novi vijek/early modern history), Željko Holjevac (moderna povijest/modern history), Tvrtko Jakovina (suvremena povijest/contemporary history),

Silvija Pisk (mikrohistorija i zavičajna povijest/microhistory and local history),

Zrinka Blažević (teorija i metodologija povijesti/theory and methodology of history)

Međunarodno uredničko vijeće / International Editorial Council

Denis Alimov (Sankt Peterburg), Živko Andrijašević (Nikšić), Csaba Békés (Budapest), Rajko Bratož (Ljubljana), Snježana Buzov (Columbus, Ohio), Svetlozar Eldarov (Sofija), Toni Filiposki (Skopje), Aleksandar Fotić (Beograd), Vladan Gavrilović (Novi Sad), Alojz Ivanišević (Wien),

Egidio Ivetić (Padova), Husnija Kamberović (Sarajevo), Karl Kaser (Graz),

Irina Ognyanova (Sofija), Géza Pálffy (Budapest), Ioan-Aurel Pop (Cluj),

Nade Proeva (Skopje), Alexios Savvides (Kalamata), Vlada Stanković (Beograd), Ludwig Steindorff (Kiel), Peter Štih (Ljubljana)

Izvršna urednica za tuzemnu i inozemnu razmjenu / Executive Editor for Publications Exchange Kristina Milković

Tajnik uredništva / Editorial Board Assistant

Dejan Zadro

Adresa uredništva/Editorial Board address

Zavod za hrvatsku povijest, Filozofski fakultet Zagreb, Ivana Lučića 3, HR-10 000, Zagreb

Tel. ++385 (0)1 6120 150, 6120 158, faks ++385 (0)1 6156879

Časopis izlazi jedanput godišnje / The Journal is published once a year

Časopis je u digitalnom obliku dostupan na / The Journal in digital form is accessible at Portal znanstvenih časopisa Republike Hrvatske „Hrčak“ http://hrcak.srce.hr/radovi-zhp

Financijska potpora za tisak časopisa / The Journal is published with the support by

Ministarstvo znanosti, obrazovanja i športa Republike Hrvatske

Časopis je indeksiran u sljedećim bazama / The Journal is indexed in the following databases:

Directory of Open Access Journals, EBSCO, SCOPUS, ERIH PLUS 
Naslovna stranica

Iva Mandić

Grafičko oblikovanje i računalni slog

Marko Maraković

Lektura

Samanta Paronić

Tisak

Web2tisak, Zagreb

Naklada

250 primjeraka

Časopis je u digitalnom obliku dostupan na Portalu znanstvenih časopisa Republike Hrvatske ,Hrčak“ http://hrcak.srce.hr/radovi-zhp

The Journal is accessible in digital form at the Hrcak - Portal of scientific journals of Croatia http://hrcak.srce.hr/radovi-zhp 


\section{RADOVI 47}

\section{vol. 1}

ZaVoda za hrVAtSku poviJest FILOZOFskoga fakulteta SVeuČILIŠTA u Zagrebu 


\title{
Tematski blok / Themed issue
}

\section{TREĆOREDSKA GLAGOLJAŠKA TRADICIJA U EUROPSKOM KONTEKSTU TERTIARY GLAGOLITIC TRADITION IN EUROPEAN CONTEXT}

\author{
Radovi međunarodnoga znanstvenog skupa \\ održanoga 27. i 28. IX. 2013. na Hrvatskom katoličkom sveučilištu u Zagrebu \\ u organizaciji \\ Provincije franjevaca trećoredaca glagoljaša u Zagrebu, Hrvatskoga katoličkog \\ sveučilišta u Zagrebu, Filozofskoga fakulteta Sveučilišta u Zagrebu - Odsjek za \\ povijest, Filozofskoga fakulteta Sveučilišta u Splitu - Odsjek za povijest, Instituta \\ za povijest umjetnosti u Zagrebu i Staroslavenskoga instituta u Zagrebu \\ Proceedings of the International Scientific Conference \\ held on 27th and 28th September 2013 at the Catholic University of Croatia in Zagreb \\ and organized by \\ the Province of the Glagolitic Friars of the Third Order Regular, Catholic University \\ of Croatia in Zagreb, Faculty of Humanities and Social Sciences of the University \\ of Zagreb - Department of History, Faculty of Humanities and Social Sciences of \\ the University of Split - Department of History, Institute of Art History, \\ and Old Church Slavonic Institute
}

Gosti urednici / Guest editors

\author{
Ivan BOTICA \\ Tomislav GALOVIĆ \\ Kristijan KUHAR
}

